\title{
A Process Optimization and Performance Study of Environmentally Friendly Waste Newspaper/Polypropylene Film Layered Composites
}

\author{
Neng Guan ${ }^{1}$, Chuanshuang $\mathrm{Hu}^{1, *}$, Litao Guan ${ }^{1}$, Weiwei Zhang ${ }^{1}$, Hong Yun ${ }^{1, *}$ and \\ Xiaojing $\mathrm{Hu}^{2}$ \\ 1 College of Materials and Energy, South China Agricultural University, Guangzhou 510642, China; \\ gn@stu.scau.edu.cn (N.G.); ltguan@scau.edu.cn (L.G.); zhangww@scau.edu.cn (W.Z.) \\ 2 College of Forestry and Horticulture, Xinjiang Agricultural University, Urumqi 830025, China; \\ hxjpyx@126.com \\ * Correspondence: cshu@scau.edu.cn (C.H.); hongy191019@yeah.net (H.Y.); Tel.: +86-020-8528-5027 (C.H.)
}

Received: 3 December 2019; Accepted: 10 January 2020; Published: 16 January 2020

\begin{abstract}
Waste newspaper are currently used in a single way and have low utilization rates. In this paper, the optimal process of preparing environmentally friendly layered composites by using waste newspaper combined with polypropylene film lamination was studied. The effects of hot-pressing temperature, hot-pressing time and paper content on the properties of the composites were analyzed. The results showed that under the process conditions of hot-pressing temperature $180^{\circ} \mathrm{C}$, compression time $20 \mathrm{~min}$ and paper content $66.7 \%$, the obtained composite material had a flexural strength of $126 \mathrm{MPa}$, a tensile strength of $95 \mathrm{MPa}$, an impact strength of $5.3 \mathrm{~kJ} / \mathrm{m}^{2}$ and a water absorption thickness expansion ratio of $3.2 \%$. Tensile performance increased by $164 \%$ compared to the original waste newspaper. Compared to our previous work, the hot processing time had been cut in half and costs were lower. In terms of creep properties, the unrecoverable strain rate was reduced by $57.5 \%$ compared to pure polypropylene. The results show that the material can maintain excellent flexural strength, tensile strength and water absorption performance while making good use of waste newspaper.
\end{abstract}

Keywords: old newspaper; polypropylene; laminated; composites; mechanical properties

\section{Introduction}

As environmental issues are increasingly concerned and the scarcity of petroleum resources, people are increasingly interested in the use of waste, and many wastes can be used as input materials for the development of other industrial new products [1], such as waste paper. China is the world's largest waste paper producer and consumer country [2]. In 2017, there were 2800 Chinese paper and paperboard manufacturers, and China's paper and paperboard production was 111.3 million tons, with a consumption of 108.97 million tons [3]. Making full use of waste paper will alleviate environmental problems and resource shortages, and bring huge economic benefits [4,5]. However, the construction of waste paper recycling, sorting, storage and transportation system in China is still relatively backward, with a low industrialization level, and the quality of waste paper recycling is poor. As a result, some waste paper is still degraded, leading to fewer waste paper utilization ways [6] and low utilization rate [7]. In May 2016, the US Forestry and Paper Association announced that the recycling rate of waste paper reached $66.8 \%$ [8], 18.7\% higher than China. Therefore, in addition to improving China's waste paper recycling system, it is increasingly important to find a way to use waste paper efficiently. The waste paper is rich in fiber, and there are a large number of polar hydroxyl groups on the surface of the paper fiber. It also has the similar structure and properties of natural plant 
fibers. Compared with natural plant fibers and synthetic fibers, they have high consistency of quality, fiber length, source and mechanical properties and are readily available [9-11].

In the waste paper recycling route, the more primitive ways are composting [12], burning and landfill. However, waste paper containing aluminum sulfate, caustic soda and other paper accessories, which will cause environmental pollution [13]. Recycled paper is a highly utilized product, but the added value of the product is low and poses a threat to the environment [14]. In recent years, researchers at home and abroad have carried out a lot of work. For example, carboxymethyl cellulose and cyanoethyl cellulose [15-18] were synthesized using waste paper. Paper fiber composites have also been prepared using waste paper as a raw material. This required smashing the newspaper and then mixing it with resin and then compounding it by extrusion molding [19-22]. The strength of the obtained material was comparable to that of the glass fiber composite. However, there are also many problems in the process, such as paper fiber tends to become flocculent after comminution, which increases the difficulty of melting and blending with the polymer matrix, and results in uneven dispersion of paper fiber in the matrix. Our research team has found that old newspaper can solve the flocculation problem with low-dose gaseous methyltrichlorosilane (MTCS) treatment [23]. Some scholars had also investigated the impact of deinking methods of waste newspapers on the properties of composite materials [24]. In addition, the interface between the fiber and the matrix is an important factor affecting the properties of the polymer composite $[25,26]$. The interaction between the hydrophilic fiber and the matrix is usually limited, while the matrix is usually hydrophobic, which leads to poor interfacial adhesion, limiting mechanical properties and affecting long-term performance at the same time. In sisal fiber (SF) reinforced HDPE composites prepared by extrusion mechanism, Xuefeng Zhao et al. explored the influence of fiber content interfacial compatibility and preparation process on its mechanical properties (tensile, impact and creep). It was found that the increase of fiber content and the compatibility of the interface with maleic anhydride grafted HDPE (MAPE) can improve the mechanical properties of the composite [19]. F. Vilaseca et al. prepared polypropylene (PP) composites from kraft fiber recovered from old bags and used Maleic anhydride grafted polypropylene (MAPP) as a coupling agent to improve the compatibility and adhesion of the fiber matrix [27]. A. Serrano et al. not only added MAPP to prepare composite materials, but also used the micromechanical and mechanical models to inversely calculate the Young's modulus inherent in composite materials [28]. But this kind of wood-plastic composite (WPC) all needs to destroy the paper fibers and blend them, which undoubtedly increases the difficulty and cost of production.

In recent years, fiber composite materials prepared by hot pressing have emerged. This method avoids the damage to the fiber, further improves the mechanical properties, and breaks through the limitation of the size of the product prepared by extrusion and extrusion process [29]. Prambauer Martina et al. used newspapers, copy paper, filter paper as raw materials, supplemented with compatibilizer maleic anhydride grafted polypropylene, respectively cross-laminated with polypropylene film and then hot-pressed to prepare paper-plastic laminated composite. The results showed that the good mechanical strength of composites prepared using copy paper and newspaper respectively, and when the volume content of paper was 30\%, the tensile and flexural strength of copy paper/PP laminated composites was the highest, about $85 \mathrm{MPa}$ and $90 \mathrm{MPa}$ [30,31]. As well as our previous research [32], high-strength laminates were prepared using newspaper layer as a reinforcing material and high density polyethylene (HDPE) film as the matrix. Such composite materials still need to be improved in terms of mechanical properties and processing efficiency. In addition, most of the research has only been carried out in theoretical scenarios, has not been linked with real products, and has not brought actual economic benefits.

In this study, it is attempted to explore the best preparation technology and mechanism by using the original waste newspaper and polypropylene film laminating compound, and obtain the composite material with better physical and mechanical properties, and the processing efficiency is further improved while achieving or exceeding the performance of similar materials. The composite material not only maintains the original shape of the newspaper, improves the utilization rate of waste paper, 
but also has a simple processing method, green environmental protection and recyclability. On the other hand, the modified high-performance composite materials can be applied to high value-added products such as sports skateboards and laminate flooring, which can not only turn waste into treasure, but also fully utilize resources and reduce the serious environmental pollution problems.

\section{Materials and Methods}

\subsection{Materials}

The used newspapers $\left(272 \mathrm{~mm} \times 390 \mathrm{~mm} \times 0.055 \mathrm{~mm}\right.$, weight: $\left.47.4 \mathrm{~g} / \mathrm{m}^{2}\right)$ were recycled from Shanghai Securities News. The content of cellulose, hemicellulose and lignin were as follows: $52.59 \%$, $26.91 \%, 15.60 \%$. The tensile strength of the newspaper was 39.5 MPa. Polypropylene film (density $0.925 \mathrm{~g} / \mathrm{cm}^{3}$, MFI $11 \mathrm{~g} / 10 \mathrm{~min}$ at $190^{\circ} \mathrm{C} / 2.16 \mathrm{~kg}$, length and width $272 \mathrm{~mm} \times 390 \mathrm{~mm}$ ) was purchased from Huizhou Bao tian Plastic Packaging Co., Ltd., Huizhou, China. The tensile strength measured was $35 \mathrm{MPa}$, the thickness was selected to be $0.022 \mathrm{~mm}, 0.025 \mathrm{~mm}, 0.03 \mathrm{~mm}, 0.04 \mathrm{~mm}, 0.055 \mathrm{~mm}$.

\subsection{Preparation Method of Composite Materials}

The newspaper and polypropylene film were assembled in the order of a newspaper and a polypropylene film, a total of 108 layers. The assembled composite material was dried in a drying box at $60{ }^{\circ} \mathrm{C}$ until the quality was constant. A hot press (XLB-600 ×600, Qingdao Goworld Rubber Machine Co., Ltd, Qingdao, China) was used to press the assembled composite material. The parameters were shown in Table 1. Among them, the paper content (wt.\%) was controlled by using polypropylene films of different thicknesses. The thickness of the product was controlled by the thickness gauge to $3 \mathrm{~mm}$. At the same time, in order to prevent the surface of the composite material from being contaminated, a PTFE film was laid on the upper and lower surfaces. After the hot-pressing process was finished, the composite material was cooled to room temperature using a circulating cooling water system and then the pressure was released.

Table 1. Single factor test table.

\begin{tabular}{ccc}
\hline Hot-Pressing Temperature $\left({ }^{\circ} \mathbf{C}\right)$ & Hot-Pressing Time $(\mathbf{m i n})$ & Paper Content $(\%)$ \\
\hline $170,180,190,200,210$ & 15 & 62.5 \\
\hline 180 & $10,15,20,30,40$ & 62.5 \\
\hline 180 & 15 & $69.4,66.7,62.5,55.6,47.6$ \\
\hline
\end{tabular}

Note: The hot-pressing pressure used was $1 \mathrm{MPa}$.

After the above process was completed, the pressure was unloaded, and the sample was taken out and equilibrated at $23^{\circ} \mathrm{C} \pm 2{ }^{\circ} \mathrm{C}$, humidity $50 \% \pm 5$ for at least $24 \mathrm{~h}$.

\subsection{Composite Material Performance Test Method}

The tensile strength of the original waste paper was tested in accordance with ASTM D828-16. Universal testing machine (ai-7000m-go, high-speed railway testing instrument (Dongguan) co., LTD., Dongguan, China) was used to conduct 10 parallel tests on each group of samples, with a gauge length of $180 \pm 5 \mathrm{~mm}$ and a test speed of $10 \mathrm{~mm} / \mathrm{min}$, to ensure that the samples broke in 10-30 s.

The flexural strength of the composite material was tested in accordance with GB/T 17657-2013. The specimen size was $150 \mathrm{~mm} \times 5 \mathrm{~mm} \times 3 \mathrm{~mm}$ and the test speed was $25 \mathrm{~mm} / \mathrm{min}$. Tensile strength was tested with reference to the first type of specimen in ASTM D638-14 at a test speed of $5 \mathrm{~mm} / \mathrm{min}$. The gauge length was $50 \mathrm{~mm}$. Izod impact strength was referenced to ATSM D256-2010 using an electronic cantilever pendulum impact tester (XJUD-5.5, Chengde Jinjian Testing Instrument Co., Ltd., Chengde, China). The $24 \mathrm{~h}$ water absorption thickness expansion rate test was carried out according to GB/T 17657-2013. 
The creep of the sample was measured using a dynamic thermomechanical analyzer (DMA 242E Artemis, NETZSCH-Gerätebau GmbH, Selbu, Germany) with a sample size of $55 \mathrm{~mm} \times 8 \mathrm{~mm} \times 3 \mathrm{~mm}$. A load of $0.42 \mathrm{MPa}$ was applied to the sample, creep behavior was observed within $40 \mathrm{~min}$, then the load was released within $40 \mathrm{~min}$ and the recovery behavior was observed.

Scanning electron microscopy (SU-70, HITACHI, Tokyo, Japan) with an acceleration voltage of $2.0 \mathrm{kV}$ was used to observe the cross-section of the composites under different process conditions. Before the observation, all the sections were sprayed with gold.

\section{Results and Analysis}

According to the experimental arrangement of Table 1, the three factors of temperature, time and paper content were carried out. Then the physical and mechanical properties of the composite were tested. Through the multivariate analysis of variance of the test results, the results showed that the hot-pressing temperature and paper content had a significant impact on the properties of the composite materials, while the hot-pressing time was not significant, as shown in Table 2.

Table 2. Analysis of variance.

\begin{tabular}{|c|c|c|c|c|c|c|c|c|c|c|c|c|c|}
\hline Variation Sources & df & \multicolumn{3}{|c|}{ Flexural Strength } & \multicolumn{3}{|c|}{ Tensile Strength } & \multicolumn{3}{|c|}{ Impact Strength } & \multicolumn{3}{|c|}{$\begin{array}{c}\text { Thickness Swelling } \\
\text { Rate of Water } \\
\text { Absorption ( } 24 \mathrm{~h})\end{array}$} \\
\hline $\begin{array}{l}\text { Hot-pressing } \\
\text { Temperature }\end{array}$ & 4 & 380.591 & 3.938 & 0.036 & 1160.629 & 41.945 & 0.00 & 11.246 & 3.322 & 0.056 & 0.700 & 0.157 & 0.955 \\
\hline Hot-pressing Time & 4 & 247.95 & 1.656 & 0.236 & 94.128 & 0.207 & 0.929 & 4.016 & 0.640 & 0.646 & 0.920 & 0.211 & 0.926 \\
\hline
\end{tabular}

Note: $\mathrm{df}$ is degree of freedom and MS is mean square; $\mathrm{F}$ is the statistic; Sig. $<0.5$ means significant.

\subsection{Effect of Hot-Pressing Temperature on the Properties of Composites}

The strong interfacial bonding of composite materials involves factors such as mechanical riveting and making fibers fully wet [33]. As shown in Figure 1, the effect of temperature on the properties of the composite material was significant. When the hot-pressing temperature rose from $170{ }^{\circ} \mathrm{C}$ to $190{ }^{\circ} \mathrm{C}$, the flexural strength, tensile strength and impact strength of the composite board reached $111 \mathrm{MPa}$ and $92 \mathrm{MPa}, 11.2 \mathrm{~kJ} / \mathrm{m}^{2}$, respectively, with corresponding increases of $8.8 \%, 4.6 \%$ and $61.9 \%$. The expansion rate of $24 \mathrm{~h}$ water absorption thickness was $1.35 \%$, which decreased by $45.6 \%$. This is because the polypropylene melts more fully with the gradual increase of temperature. Under the action of pressure, the fluidity is enhanced, which can penetrate into the pores of the newspaper better and strengthen with the mechanical riveting of the newspaper. This explanation was also mentioned in related articles [22]. When the hot-pressing temperature was increased from $190{ }^{\circ} \mathrm{C}$ to $210{ }^{\circ} \mathrm{C}$, the material properties began to decrease. The flexural strength, tensile strength, impact strength and $24 \mathrm{~h}$ water absorption thickness expansion ratio of the composite sheet were $79 \mathrm{MPa}, 35 \mathrm{MPa}$, $1.8 \mathrm{~kJ} / \mathrm{m}^{2}$ and $0.80 \%$ respectively, correspondingly reduced by $29.1 \%, 62.2 \%, 83.7 \%$, and $40.7 \%$. This is mainly due to the large amount of oxidation, dehydration and $\beta$-alkoxy elimination of cellulose at high temperatures, and the higher the temperature, the faster the degradation rate of cellulose [34].When the hot-pressing temperature reached $200^{\circ} \mathrm{C}$, the functional groups which are easily oxidized by hydroxyl groups on the paper fibers are rapidly oxidized, the number of hydrogen bonds formed between the molecules is reduced, and the binding force between the molecules is lowered, resulting in a decrease in the performance of the newspaper substrate. The $24 \mathrm{~h}$ water absorption thickness expansion rate was always in a lower state after $180^{\circ} \mathrm{C}$. the increase in temperature is more conducive to the melting of polypropylene and penetration in newspaper, thus having a better embedding effect on the newspaper layer. Therefore, $180^{\circ} \mathrm{C}$ was selected as the experimental temperature in the following experiments. 


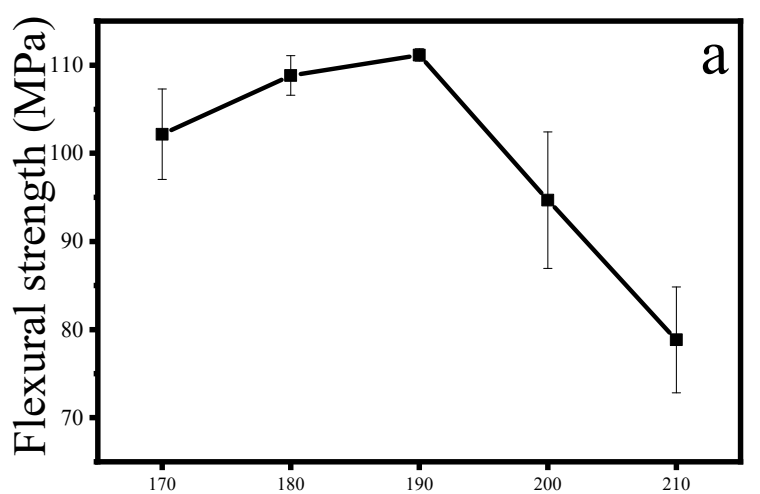

Hot-pressing temperature $\left({ }^{\circ} \mathrm{C}\right)$

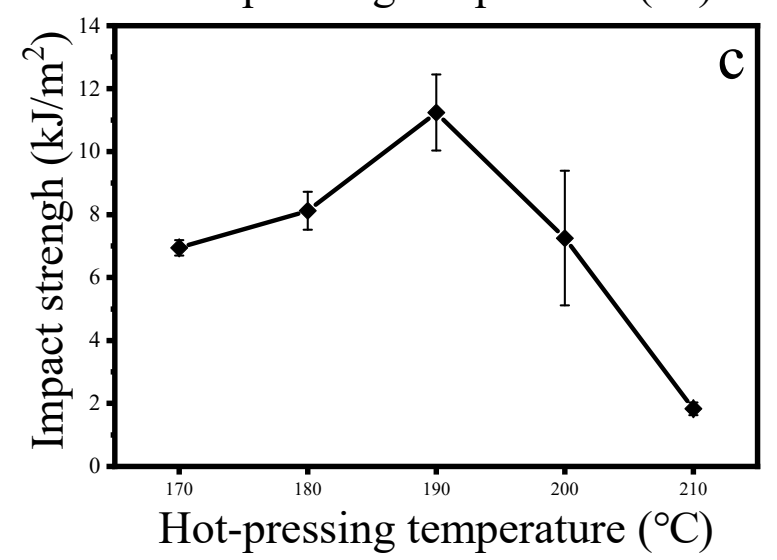

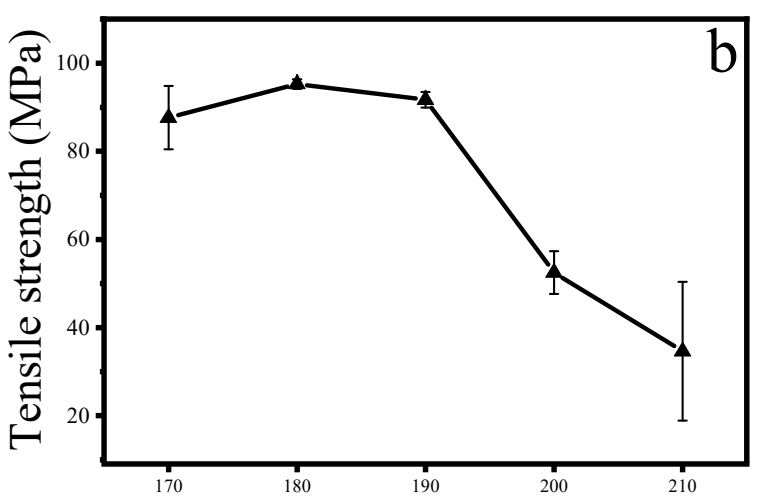

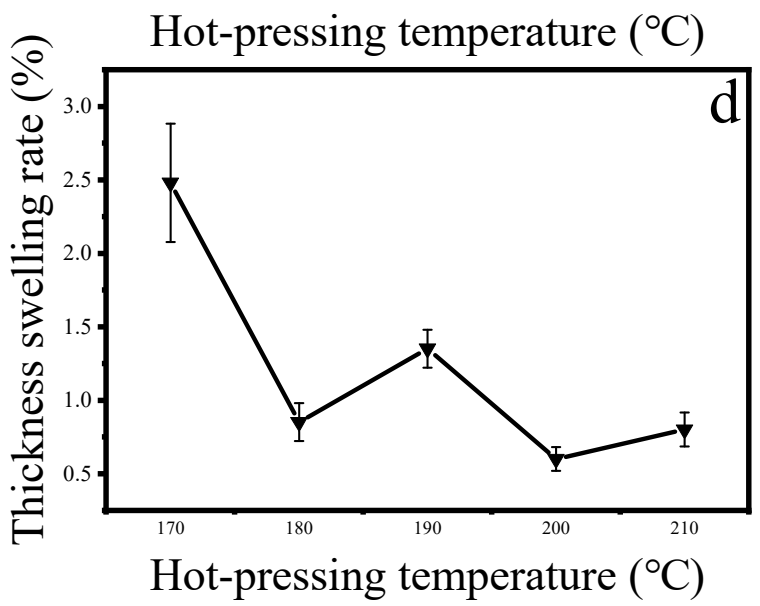

Figure 1. Effect of hot-pressing temperature on different properties of composite plates: (a) flexural strength; (b) tensile strength; (c) impact strength; (d) thickness swelling rate.

\subsection{Effect of Hot-Pressing Time on the Properties of Composites}

During the hot-pressing process, the heat in the plate is transferred from the upper and lower plates to the center layer of the composite material. The heat transfer speed is determined by the hot -pressing temperature and the hot-pressing time. When the hot-pressing temperature was $180{ }^{\circ} \mathrm{C}$ and the hot- pressing time was increased from $10 \mathrm{~min}$ to $20 \mathrm{~min}$, the flexural strength and tensile strength of the composite material reached $129 \mathrm{MPa}$ and $99 \mathrm{MPa}$, respectively, which were $24.8 \%$ and $2.6 \%$ higher than $10 \mathrm{~min}$, respectively. This is because increase in hot-pressing time at a certain temperature can make the polypropylene melt more fully and penetrate the newspaper better. In the pores, a riveting structure is formed to achieve a better bonding effect between polypropylene and the paper layer. However, when the hot-pressing time was increased from $20 \mathrm{~min}$ to $40 \mathrm{~min}$, the flexural strength and tensile strength of the composite panel were changed to $117 \mathrm{MPa}$ and $84 \mathrm{MPa}$ respectively, which were reduced by $9.2 \%$ and $15.8 \%$. This is because the excessive heating time caused the newspaper to oxidize, resulting in a decline in the performance of the newspaper itself. Oxidation and decomposition occur in paper fibers under heating and pressure conditions of $180^{\circ} \mathrm{C}$. Although the degree is not high, the strength decreases with time. Therefore, the flexural strength and tensile strength in Figure 2 have a tendency to decrease with time, but they are not as severe as those in Figure 1. The excessively long hot-pressing time causes the hydrophilic hydroxyl groups on the paper fibers to be partially oxidized, resulting in weakening of the intermolecular forces, and water molecules are more likely to enter the matrix, and the water absorbing thickness expansion rate is increased. Similarly, the excessive heating time reduced the impact strength. From $10 \mathrm{~min}$ to $15 \mathrm{~min}$, the impact strength increased by $32.5 \%$, but then began to decrease. During the experiment, the composite paper turned yellow and became brittle, which also illustrated the above points. 

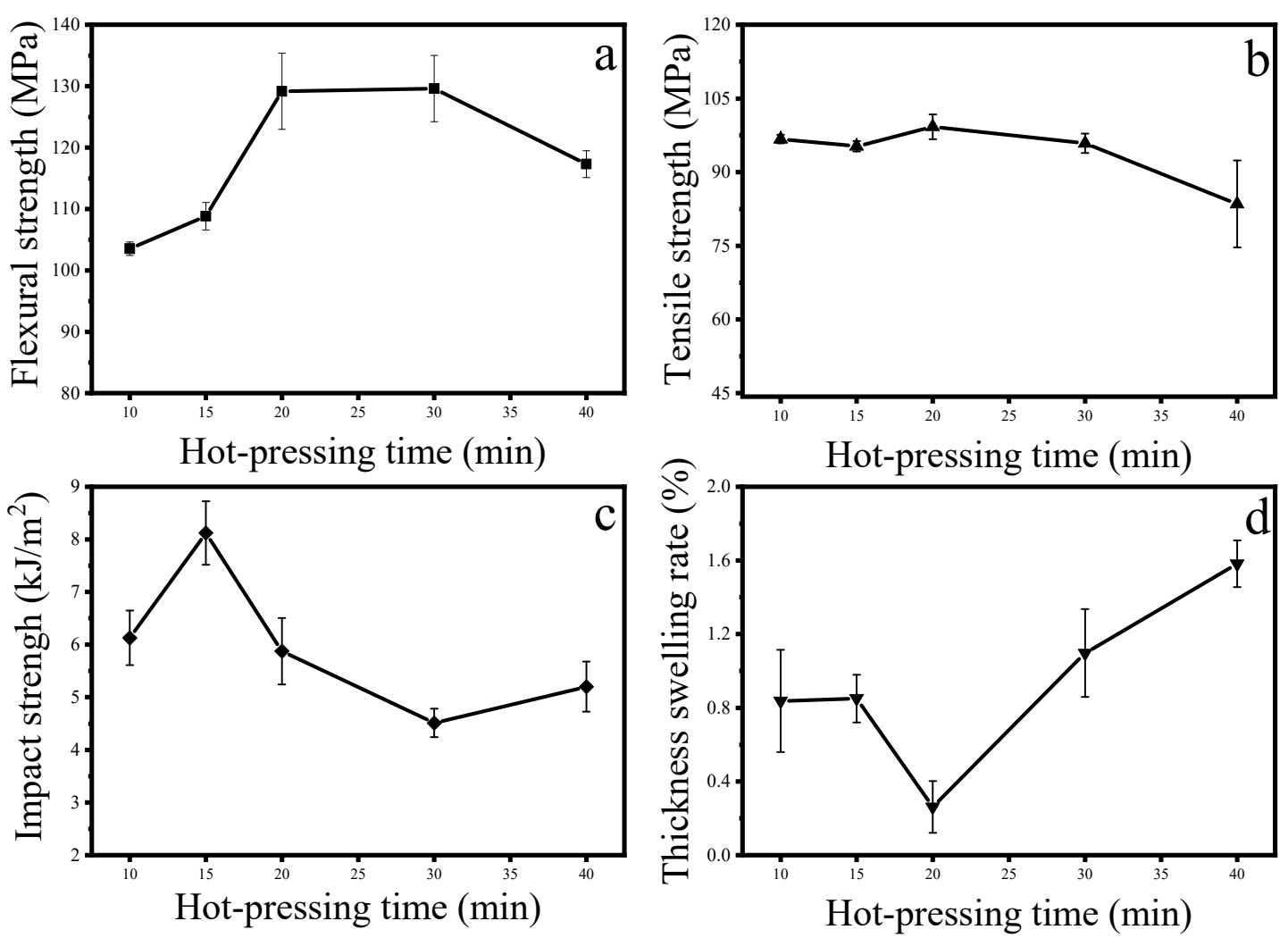

Figure 2. Effect of hot-pressing time on the performance of composite panels: (a) flexural strength; (b) tensile strength; (c) impact strength; (d) thickness swelling rate.

\subsection{Effect of Paper Content on the Properties of Composites}

As shown in Figure 3, the flexural strength, tensile strength and impact strength of the composites increased with the increase of the paper content, and then decreased, because the plant cellulose rigidity is much larger than that of the pure polypropylene [35]. According to the law of mixing, the total mechanical properties of the two increase with the increase of paper content. However, when the paper content was higher than $66.7 \%$, the mechanical properties were degraded. In the composite material, the newspaper fiber plays a major mechanical strength, and the polypropylene content is too small to sufficiently penetrate and rivet the paper fiber, so the mechanical properties are degraded.

The influence of paper content on the swelling ratio of water absorption thickness of composite materials was very significant. When the paper content was more than $62.5 \%$, the swelling of water absorption thickness increased rapidly. This is due to the gradual reduction of polypropylene content and mechanical riveting cooperation. With the weakening, the exposed hydroxyl groups also increase, and the water absorption thickness expansion rate increases. In addition, the four sides of the test piece were not edge-sealed in the experiment, so the water absorption problem could be improved by the edge-sealing treatment in actual use. According to the above results, too high or too low paper content will have adverse effects on composite materials.

\subsection{Creep Performance}

Figure 4 shows the creep properties of composites at different temperatures $\left(180^{\circ} \mathrm{C}, 190^{\circ} \mathrm{C}\right)$ and different paper contents $(62.5 \%, 66.7 \%)$. In the process of loading a constant force, polypropylene was most deformed compared to composite materials because the rigidity of cellulose in newspaper is greater than that of pure polypropylene [35]. The rise in the hot-pressing temperature increased the deformation of the composite material. The higher the temperature, the greater the degree of oxidation of the paper fibers, resulting in a decrease in mechanical strength. Therefore, the deformation of B was greater than D. At the same hot -pressing temperature, too little polypropylene makes it not penetrate 
well into the pores of the newspaper and forms a coating, which increases the deformation of the material, as shown in D and E in Figure 4. After the load was removed, the irreversible deformation of the polypropylene was the largest, reaching $1.17 \%$. The composite material, due to the mechanical riveting between the polypropylene and the newspaper, limits the slip of the polypropylene molecular chain and reduces the irreversible deformation. When the hot-pressing temperature was $180^{\circ} \mathrm{C}$ and the paper content was $62.5 \%$, the irreversible shape of the composite material became $0.415 \%$, which was the non-reversible shape minimum value.
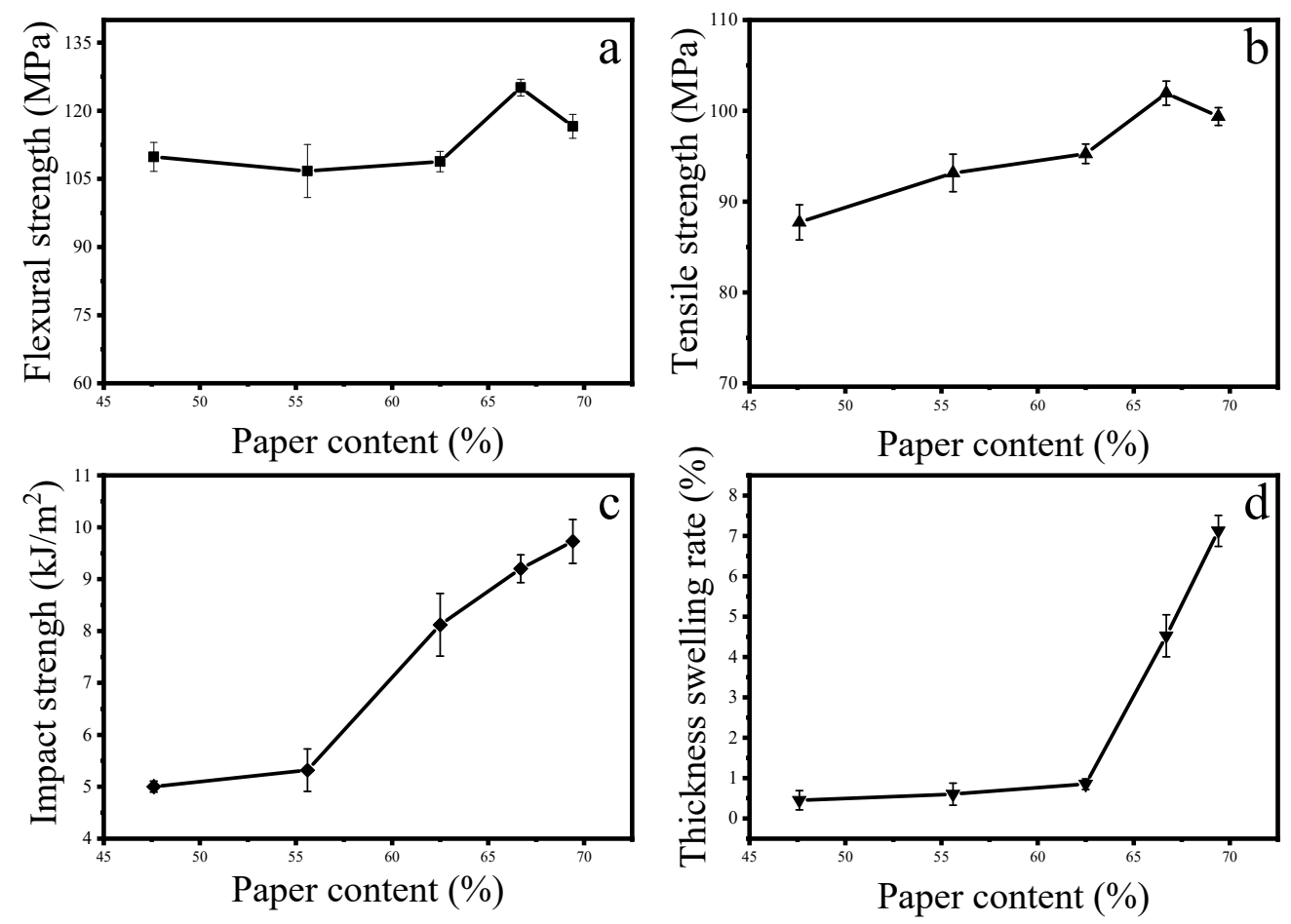

Figure 3. Effect of paper content on the properties of composites: (a) flexural strength; (b) tensile strength; (c) impact strength; (d) thickness swelling rate.

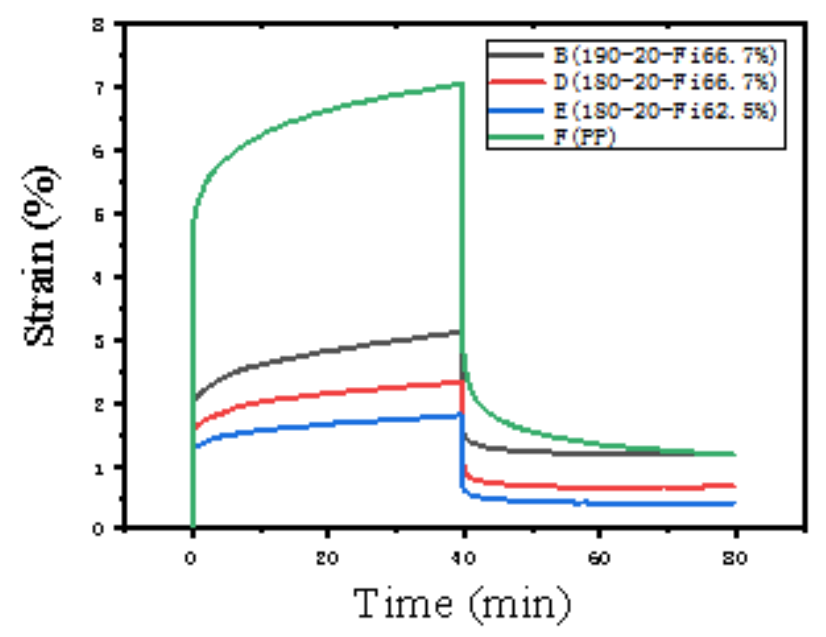

Figure 4. Creep curve of composite material and polypropylene: (B) the hot-pressing temperature was $190^{\circ} \mathrm{C}$, the hot-pressing time was $20 \mathrm{~min}$, and the paper content was $66.7 \%$; (D) the hot-pressing temperature was $180{ }^{\circ} \mathrm{C}$, the hot-pressing time was $20 \mathrm{~min}$, and the paper content was $66.7 \%$; (E) the hot-pressing temperature was $180^{\circ} \mathrm{C}$, the hot-pressing time was $20 \mathrm{~min}$, and the paper content was $62.5 \%$; (F) the hot-pressing temperature is $180^{\circ} \mathrm{C}$ and the hot-pressing time is $20 \mathrm{~min}$. 


\subsection{Microscopic Morphology of Composite Materials}

The microstructure of the composites at different temperatures and different paper contents was observed by SEM. As shown in Figure 5a-c, the hot-pressing temperature had a large effect on the permeability of polypropylene. At $170{ }^{\circ} \mathrm{C}$, there was a large amount of porosity in the composite paper fiber layer (Figure 5a, and the effect of pressure did not completely press the paper fibers to compact. As the temperature increased, the polypropylene penetrated better into the pores of the newspaper (Figure $5 b, c$ ). When the temperature reached $190^{\circ} \mathrm{C}$ or higher, the gap between the newspaper fibers was substantially filled. The melting point of polypropylene is $162.12^{\circ} \mathrm{C}$, so the increase in temperature contributes to the flow of polypropylene. As shown in Figure $5 \mathrm{~d}-\mathrm{f}$, the influence of paper content on the penetration of polypropylene was not obvious. When the paper content increased from $47.6 \%$ to $62.5 \%$, SEM of the composite cross section showed that there were relatively uniform and complete polypropylene penetration and adhesion in the paper layer. Natural fibers are hydrophilic and polypropylene is hydrophobic, which prevents good compatibility between the two phases [36]. When the paper content was more than $62.5 \%$, the reduction of polypropylene exacerbated this phenomenon, and a small amount of voids appeared between the layers (Figure 5f). Thus, excessively high paper content adversely affected the mechanical properties of the composite, and this result was consistent with 3.3.
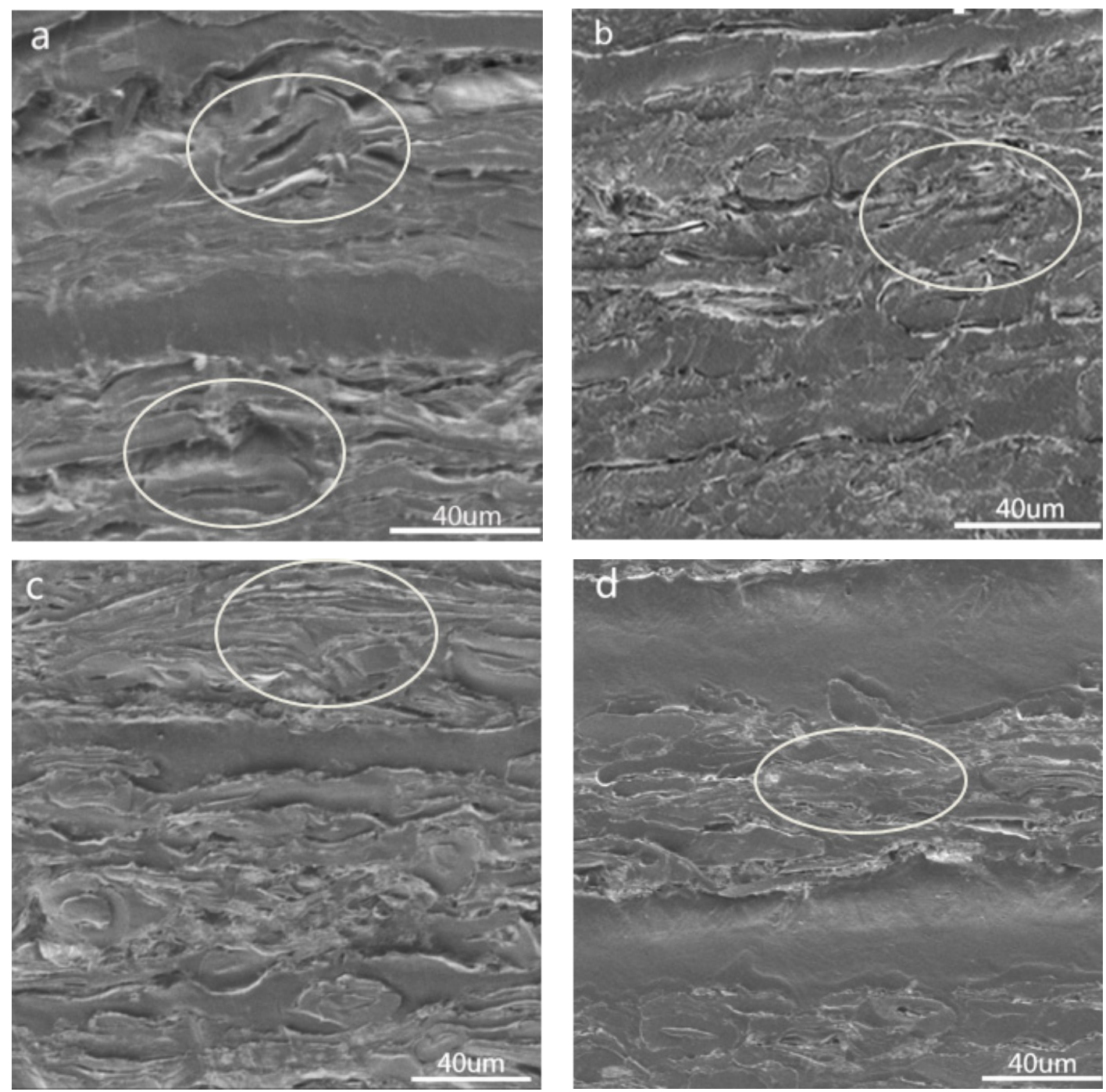

Figure 5. Cont. 

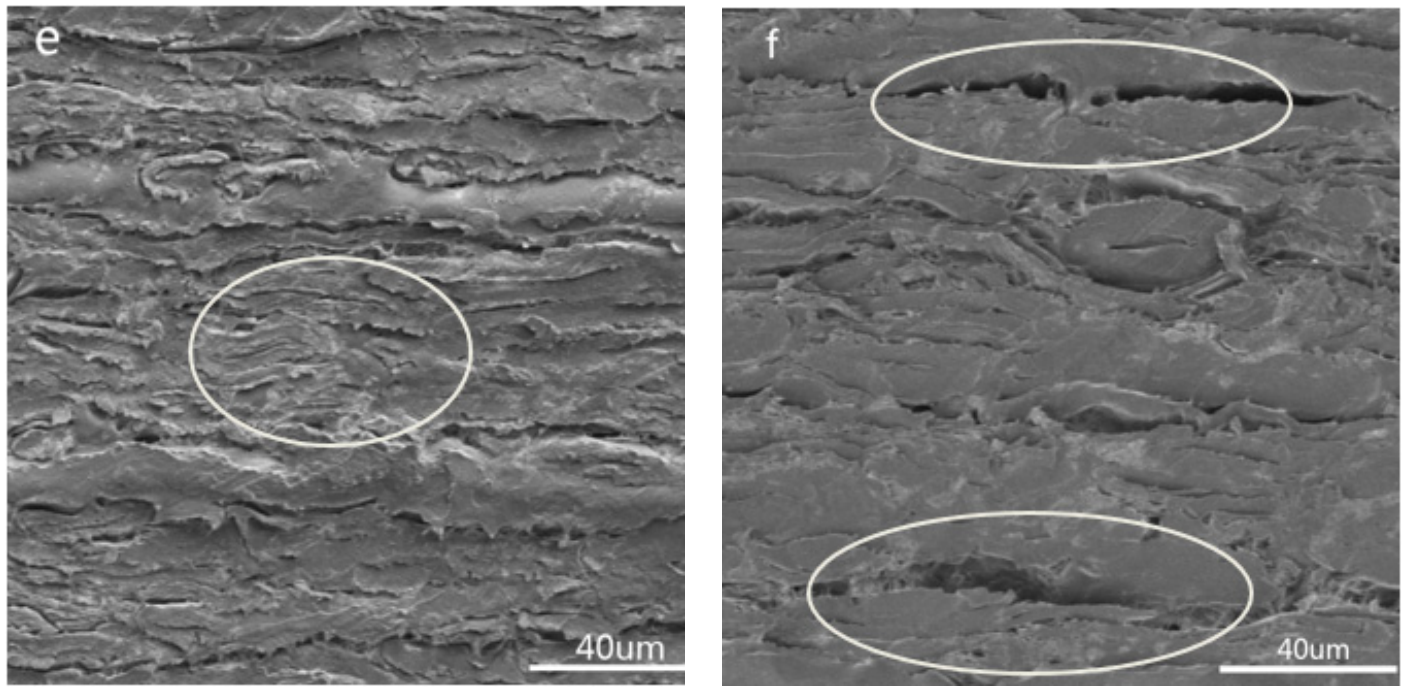

Figure 5. Microscopic morphology after magnifying 500 times of composite materials at different temperatures and different paper contents: (a) hot-pressing temperature: $170{ }^{\circ} \mathrm{C}$; (b) hot pressing temperature: $190{ }^{\circ} \mathrm{C}$; (c) hot-pressing temperature: $200{ }^{\circ} \mathrm{C}$; (d) paper content: $47.6 \%$; (e) paper content: $62.5 \%$; (f) paper content: $69.4 \%$.

\section{Conclusions}

In this study, environmentally friendly paper-plastic laminated composite panels were prepared by using waste paper and polypropylene film as raw materials, and the effects of hot-pressing process parameters and paper content on the properties of layered composite sheets were studied. Through single factor experiments, it was found that hot-pressing temperature and paper content had significant effects on the mechanical properties of composites. Too high temperature will make paper fiber oxidation, too low temperature will be not conducive to the flow and penetration of polypropylene. Therefore, the optimum process for determining the newspaper/polypropylene layered composite material was hot-pressing temperature of $180{ }^{\circ} \mathrm{C}$, hot-pressing time of $20 \mathrm{~min}$, and paper content of $66.7 \%$. The tensile strength and flexural strength of the obtained composite material were nearly three times higher than polypropylene, and the creep resistance was nearly doubled than polypropylene. The utilization rate of newspaper was further improved. Compared with the method of crushing newspapers for extrusion production [23], the flexural strength and tensile strength of the obtained materials had been increased by nearly $260 \%$ and $188 \%$, respectively (the performance value under the optimal conditions of each process). It is shown that the use of the entire sheet of paper can help to improve some of the mechanical properties of the composite material. Compared to our previous work [32], the hot processing time had been cut in half and costs were lower. The composite material is of great significance for promoting the recycling of waste paper and improving the performance of polymer materials.

Author Contributions: Conceptualization, C.H., H.Y. and L.G.; methodology, H.Y. and L.G; validation, N.G.; formal analysis, N.G. and W.Z.; investigation, N.G.; resources, C.H.; data curation, N.G.; writing-original draft preparation, N.G.; writing-review and editing, H.Y., X.H. and L.G.; visualization, N.G. and W.Z.; supervision, H.Y. and L.G.; project administration, L.G.; funding acquisition, C.H. All authors have read and agreed to the published version of the manuscript.

Funding: This research was funded by Guangdong Provincial Department of Science and Technology Project [2017B020238003] and the Guangdong Forestry Science and Technology Innovation Project [2018KJCX004-03].

Conflicts of Interest: The authors declare no conflict of interest. 


\section{References}

1. Singh, S.; Ramakrishna, S.; Gupta, M.K. Towards zero waste manufacturing: A multidisciplinary review. J. Clean Prod. 2017, 168, 1230-1243. [CrossRef]

2. Liang, S.; Zhang, T.; Xu, Y. Comparisons of four categories of waste recycling in China's paper industry based on physical input-output life-cycle assessment model. Waste Manag. 2012, 32, 603-612. [CrossRef]

3. China Paper Industry. China Paper Industry 2017 Annual Report. Pap. Pap. 2018, 37, 56-62.

4. $\mathrm{Xu}, \mathrm{H}$. On the practice and exploration of waste paper raw material acquisition in papermaking enterprises. China Pap. Ind. 2017, 38, 39-42.

5. Sinha, M.; Engineering, B.E.M. Identifying Standardized Data for Manufacturing Commercial Grade Pencils Made Out of Recycled or Waste Paper with Qualities Comparable to Wooden Pencils. Int. J. Mech. Eng. Inf. Technol. 2016, 4, 1798-1805. [CrossRef]

6. Liu, K. Status and prospect of waste paper recycling system in China. Renew. Resour. Recycl. Econ. 2013, 6, 24-27.

7. Li, W.; Wan, L.; Yuan, L. Influence factors of waste paper import trade in China. For. Econ. 2018, 38, 21-26.

8. Zhang, Q. Set waste paper recycling target, which greatly promoted the improvement of waste paper recycling rate. Pap. Inf. 2017, 70, 70.

9. Monte, M.C.; Fuente, E.; Blanco, A.; Negro, C. Waste management from pulp and paper production in the European Union. Waste Manag. 2009, 29, 293-308. [CrossRef] [PubMed]

10. He, L. Research on Polyolefin/Paper Powder Composites. Master's Thesis, Dalian University of Technology, Dalian, China, 2009.

11. Burgstaller, C.; Rüf, W.; Stadlbauer, W.; Pilz, G.; Lang, R.W. Utilizing Unbleached Cellulosic Fibres in Polypropylene Matrix Composites for Injection Moulding Applications. J. BioBased Mater. Bioenergy 2009, 3, 226-231. [CrossRef]

12. Alvarez, J.V.L.; Larrucea, M.A.; Bermúdez, P.A.; Chicote, B.L. Biodegradation of paper waste under controlled composting conditions. Waste Manag. 2009, 29, 1514-1519. [CrossRef] [PubMed]

13. Zhang, X.; Cao, C.; Bo, X. Effects of paper, ink, and printing methods on secondary fiber recycling performance. Heilongjiang Pap. 2006, 34, 26-29. [CrossRef]

14. Gu, L. Deinked Recycled Paper Manufacturing Environmentally Friendly Coated Paper. Master's Thesis, Tianjin University of Science and Technology, Tianjin, China, 2015.

15. Joshi, G.; Naithani, S.; Varshney, V.K.; Bisht, S.S.; Rana, V.; Gupta, P.K. Synthesis and characterization of carboxymethyl cellulose from office waste paper: A greener approach towards waste management. Waste Manag. 2015, 38, 33-40. [CrossRef] [PubMed]

16. Ünlü, C.H. Carboxymethylcellulose from recycled newspaper in aqueous medium. Carbohyd. Polym. 2013, 97, 159-164. [CrossRef] [PubMed]

17. Barba, C.; Reguant, J.; Farriol, X.; Montané, D. Carboxymethyl Cellulose from Waste Lignocellulosic Pulps Produced by a Fast Soda/Aq Process. J. Wood Chem. Technol. 2000, 20, 185-204. [CrossRef]

18. Joshi, G.; Naithani, S.; Varshney, V.K.; Bisht, S.S.; Rana, V. Potential use of waste paper for the synthesis of cyanoethyl cellulose: A cleaner production approach towards sustainable environment management. J. Clean Prod. 2017, 142, 3759-3768. [CrossRef]

19. Zhao, X.; Li, R.K.Y.; Bai, S. Mechanical properties of sisal fiber reinforced high density polyethylene composites: Effect of fiber content, interfacial compatibilization, and manufacturing process. Compos. Part $A$ Appl. Sci. Manuf. 2014, 65, 169-174. [CrossRef]

20. Huda, M.; Drzal, L.; Mohanty, A.; Misra, M. Chopped glass and recycled newspaper as reinforcement fibers in injection molded poly(lactic acid) (PLA) composites: A comparative study. Compos. Sci. Technol. 2006, 66, 1813-1824. [CrossRef]

21. Feng, D.; Caulfield, D.F.; Sanadi, A.R. Effect of compatibilizer on the structure-property relationships of kenaf-fiber/polypropylene composites. Polym. Compos. 2001, 22, 506-517. [CrossRef]

22. Tarrés, Q.; Soler, J.; Rojas-Sola, J.I.; Oliver-Ortega, H.; Julián, F.; Espinach, F.X.; Mutjé, P.; Delgado-Aguilar, M. Flexural Properties and Mean Intrinsic Flexural Strength of Old Newspaper Reinforced Polypropylene Composites. Polymers 2019, 11, 1244. [CrossRef]

23. Zhang, W.; Gu, J.; Tu, D.; Guan, L.; Hu, C. Efficient Hydrophobic Modification of Old Newspaper and Its Application in Paper Fiber Reinforced Composites. Polymers 2019, 11, 842. [CrossRef] [PubMed] 
24. Zhang, X.; Bo, X.; Cong, L.; Wei, L.; McDonald, A.G. Characteristics of undeinked, alkaline deinked, and neutral deinked old newspaper fibers reinforced recycled polypropylene composites. Polym. Compos. 2018, 39, 3537-3544. [CrossRef]

25. Kashfipour, M.A.; Mehra, N.; Zhu, J. A review on the role of interface in mechanical, thermal, and electrical properties of polymer composites. Adv. Compos. Hybrid. Mater. 2018, 1, 415-439. [CrossRef]

26. Li, Y.; Yi, X.; Yu, T.; Xian, G. An overview of structural-functional-integrated composites based on the hierarchical microstructures of plant fibers. Adv. Compos. Hybrid. Mater. 2018, 1, 231-246. [CrossRef]

27. Vilaseca, F.; Méndez, J.A.; López, J.P.; Vallejos, M.E.; Barberà, L.; Pèlach, M.A.; Turon, X.; Mutjé, P. Recovered and recycled Kraft fibers as reinforcement of PP composites. Chem. Eng. J. 2008, 138, 586-595. [CrossRef]

28. Serrano, A.; Espinach, F.X.; Tresserras, J.; Del Rey, R.; Pellicer, N.; Mutje, P. Macro and micromechanics analysis of short fiber composites stiffness: The case of old newspaper fibers-polypropylene composites. Mater. Des. 2014, 55, 319-324. [CrossRef]

29. Benthien, J.T.; Thoemen, H. Effects of raw materials and process parameters on the physical and mechanical properties of flat pressed WPC panels. Compos. Part A Appl. Sci. Manuf. 2012, 43, 570-576. [CrossRef]

30. Prambauer, M.; Paulik, C.; Burgstaller, C. The influence of paper type on the properties of structural paper-Polypropylene composites. Compos. Part A Appl. Sci. Manuf. 2015, 74, 107-113. [CrossRef]

31. Prambauer, M.; Paulik, C.; Burgstaller, C. Evaluation of the interfacial properties of polypropylene composite laminates, reinforced with paper sheets. Compos. Part A Appl. Sci. Manuf. 2016, 88, 59-66. [CrossRef]

32. Zheng, B.; Hu, C.; Guan, L.; Gu, J.; Guo, H.; Zhang, W. Structural Characterization and Analysis of High-Strength Laminated Composites from Recycled Newspaper and HDPE. Polymers 2019, 11, 1311. [CrossRef]

33. Reixach, R.; Franco-Marquès, E.; El Mansouri, N.; Ramirez De Cartagena, F.; Arbat, G.; Espinach, F.X.; Mutjé, P. Micromechanics of Mechanical, Thermomechanical, and Chemi-Thermomechanical Pulp from Orange Tree Pruning as Polypropylene Reinforcement: A Comparative Study. Bioresources 2013, 8, 3231-3246. [CrossRef]

34. Łojewski, T.; Miśkowiec, P.; Molenda, M.; Lubańska, A.; Łojewska, J. Artificial versus natural ageing of paper. Water Role Degrad. Mech. Appl. Phys. A 2010, 100, 625-633. [CrossRef]

35. Baroulaki, I.; Karakasi, O.; Pappa, G.; Tarantili, P.A.; Economides, D.; Magoulas, K. Preparation and study of plastic compounds containing polyolefins and post used newspaper fibers. Compos. Part A Appl. Sci. Manuf. 2006, 37, 1613-1625. [CrossRef]

36. Granda, L.A.; Espinach, F.X.; López, F.; García, J.C.; Delgado-Aguilar, M.; Mutjé, P. Semichemical fibres of Leucaena collinsii reinforced polypropylene: Macromechanical and micromechanical analysis. Compos. Part B Eng. 2016, 91, 384-391. [CrossRef] 